\title{
Analysis of Failure Criteria in Laminas Reinforced with Unidirectional Curaua Fiber Fabric
}

\author{
Lucemaide Batista Miranda Ferreira ${ }^{a}$, Raimundo Carlos Silverio Freire Júnior ${ }^{a}$ *D,
}

\author{
Elmo Thiago Lins Cöuras Ford ${ }^{a}$
}

\author{
${ }^{a}$ Centro de Tecnologia, Programa de Pós-Graduação em Engenharia Mecânica,Universidade Federal \\ do Rio Grande do Norte, 59072-970, Lagoa Nova, Natal, RN, Brasil
}

Received: June 19, 2018; Revised: February 21, 2019; Accepted: March 28, 2019

\begin{abstract}
Natural fibers are increasingly used as composite reinforcement in different fields of engineering. Caraua fiber stands out for its good mechanical properties and adherence to resin; however, little is known about its behavior in the manufacture of a composite or whether classic failure theory applies in this case. The present study assesses the mechanical properties of two laminas reinforced with unidirectional curaua fiber containing fiber volume fractions of $30 \%$ and $22 \%$, and compares the results with the values obtained for four failure criteria, using analysis of variance (ANOVA). To that end, tensile tests were conducted along the fiber direction and at other loading angles, in addition to iosipescu shear tests. The results show that the Hashin criterion was the best and the maximum stress criterion does not represent the failure behavior of these materials.
\end{abstract}

Keywords: failure criteria, curaua fibers, ANOVA.

\section{Introduction}

Natural fibers have been increasingly used in engineering applications, due to their low density, high mechanical strength, low cost and renewability.

As such, natural fibers may be a viable option in the manufacture of composites, substituting costly synthetic materialswith a renewable source. Indeed, natural fibers have partially and in some applications completely replaced synthetic fibers $^{1-5}$.

Curaua has attracted considerable attention in Brazil, whose plant fibers also include cotton, jute, ramie and coconut. This light-weight fiber originates in the Amazon and exhibits excellent mechanical properities ${ }^{6}$, with potential applications in the automobile industry due to its strength and rigidity. It has been applied as reinforcement in polymer composites, because of its superior mechanical properties compared to other natural fibers such as jute and $\operatorname{cotton}^{7-10}$.

However, for a natural fiber-reinforced composite to be used structurally, its predicted failure and engineering constants must be determined, given that structures are normally submitted to biaxial or triaxial stresses. As such, failure theories previously developed for orthotropic materials must be applied and assessed for this particular case. To that end, analysis of variance ( $A N O V A$ ) was conducted to determine the most suitable failure theory. That is, a more detailed study of natural fiber-based composites is needed in order to apply them in projects and structures, which is the object of study of this paper.

The present study investigates two unidirectional curaua/ polyester laminas with different volume fractions, analyzing failure in several fiber directions based on four failure criteria: maximum stress, Tsai-Wu, Tsai-Hill and Hashin. Different

*e-mail: freirej@ufrnet.br test specimens were submitted to tensile and shear tests and the behavior of the material was examined based on data from the tested samples.

\section{Failure criteria studied}

\subsection{Maximum stress criterion}

The maximum stress criterion ${ }^{11}$ assumes that the stresses applied in the main material directions must be lower than those in the load directions to prevent rupture. The safety limits for this criterion are presented in equation 1 :

$$
\begin{aligned}
& -X_{C} \leq \sigma_{1} \leq X_{T} \\
& -Y_{C} \leq \sigma_{2} \leq Y_{T} \\
& \left|\tau_{12}\right| \leq S
\end{aligned}
$$

Where $X_{T}, X_{C}, Y_{T}, Y_{C}$ and $S$ are the strength values obtained in experimental tests, as follows: $X_{T}$ is longitudinal tensile strength; $X_{C}$ the longitudinal compressive strength; $Y_{T}$ the transverse tensile strength; $Y_{C}$ the transverse compressive strength; $S$ the in-plane shear strength and $\sigma_{1}, \sigma_{2}$ and $\tau_{12}$ the normal $\left(\sigma_{1}, \sigma_{2}\right)$ and shear stresses $\left(\tau_{12}\right)$ applied (Figure 1a).
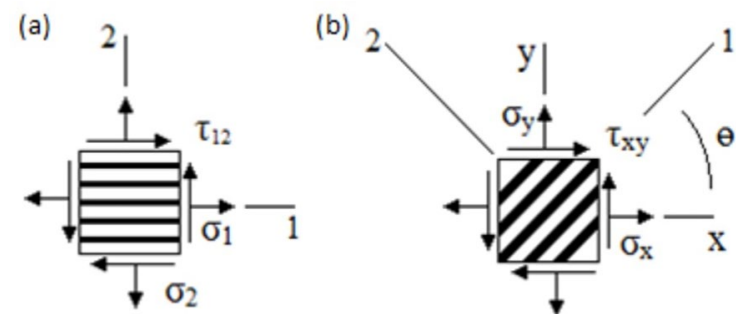

Figure 1. (a) Stresses in direction 1 and 2 (parallel and perpendicular to the fiber). (b) Stresses in direction $\mathrm{x}$ and $\mathrm{y}$ (loading angle in relation to the fiber). 
Although this criterion is easy to apply, it does not consider the combined effects of load, a common occurrence with any structural element.

\subsection{Tsai-Hill failure criterion}

This criterion is based on a generalization of the maximum distortion theory (Von-Mises criterion) applied to isotropic materials ${ }^{12}$, where the material has different boundary conditions (strength values), depending on the type of load applied. When a unidirectional lamina is under plane stress, it does not fracture if the stresses are equal to those of equation $2^{13-14}$.

$$
\frac{\sigma_{1}^{2}}{X^{2}}+\frac{\sigma_{2}^{2}}{Y^{2}}-\frac{\sigma_{1} \sigma_{2}}{X^{2}}+\frac{\tau_{12}^{2}}{S^{2}} \leq 1
$$

For this equation, the behavior of the material is equal to both tension and compression $\left(X_{T}=X_{c}\right.$ denominated $X$ and $Y_{T}=Y_{C}$ denominated $Y$ ).

\subsection{Tsai-Wu failure criterion}

Tsai and $\mathrm{Wu}^{15}$ proposed a method that includes $2^{\text {nd }}, 4^{\text {th }}$ and $9^{\text {th }}$ order tensors (whereas a constant was previously used in the Tsai-Hill criterion), bringing the equation even closer to the experimental data. Since analyzing such a complex model wasunfeasible, Tsai and $\mathrm{Wu}^{15}$ simplified it. Thus, for the case of plane stress where $X_{T}=X_{c}$ and $Y_{T}=Y_{C}$, the model is reduced to equation 3 .

$$
\frac{\sigma_{1}^{2}}{X^{2}}-\frac{\sigma_{1} \sigma_{2}}{X Y}+\frac{\sigma_{2}^{2}}{Y^{2}}+\frac{\tau_{12}^{2}}{S^{2}} \leq 1
$$

In equation 3, the Tsai-Wu and Tsai-Hill criteria are similar, and only the second term of the two equations is different.

\subsection{Hashin failure criterion}

In contrast to the previous criteria, the Hashin criterion considers the failure method, distinguishing between fiber and matrix failure, and whether it occurs by tension or compression. It can be simplified into two equations (equation 4 and 5) for the case of plane stress under tension, where equation 4 represents fiber-based failure and equation 5 its matrix-based counterpart ${ }^{16}$.

$$
\begin{aligned}
& \left(\frac{\sigma_{1}}{X}\right)^{2}+\left(\frac{\tau_{12}}{S}\right)^{2} \leq 1 \\
& \left(\frac{\sigma_{2}}{Y}\right)^{2}+\left(\frac{\tau_{12}}{S}\right)^{2} \leq 1
\end{aligned}
$$

\subsection{Stress vector transformation}

The values obtained from the mechanical properties of an orthotropic lamina are directly related to the fiber direction in the composite. As such, it is important to rememberthat the classic equations that relate the stress applied to the material $\left(\sigma_{x}, \sigma_{y}, \tau x y\right)$ and its anglen relation to the fiber $(\theta)$ (Figure 1), with normal stresses in the fiber direction $\left(\sigma_{1}\right)$, perpendicular to it $\left(\sigma_{2}\right)$, and shear stress $\left(\tau_{12}\right)$, using equation 6 .

$$
\left\{\begin{array}{l}
\sigma_{1} \\
\sigma_{2} \\
\tau_{12}
\end{array}\right\}=\left[\begin{array}{lrr}
\cos ^{2}(\theta) & \sin ^{2}(\theta) & 2 \sin (\theta) \cos (\theta) \\
\sin ^{2}(\theta) & \cos ^{2}(\theta) & -2 \sin (\theta) \cos (\theta) \\
-\sin (\theta) \cos (\theta) & \sin (\theta) \cos (\theta) & \cos ^{2}(\theta)-\sin ^{2}(\theta)
\end{array}\right]\left[\begin{array}{l}
\sigma_{x} \\
\sigma_{y} \\
\tau_{x y}
\end{array}\right\}
$$

Given that all the tests conducted here were uniaxial $\left(\sigma_{y}=0\right.$ and $\tau_{x y}=0$ ), this equation can be incorporated into the equations of each of the previously demonstrated failure criteria for each angle studied, comparing the ultimate tensile strength of the material in off-axis loading with the value obtained by failure criteria.

\section{Materials and Methods}

\subsection{Materials used}

To manufacture the lamina (composite with one reinforcing layer) curau was used as fiber reinforcement and unsaturated orthophthalic polyester resin as polymer matrix, with Novapol - L20 technical data sheets. Methyl ethyl ketone (MEKP) was used as an agent of the catalytic system (curing at room temperature).

Fibers with an average length of $700 \mathrm{~mm}$ were selected. After the fibers were washed, strands were obtained to manufacture $400 \times 400 \mathrm{~mm}$ unidirectional fabrics. Figure 2a shows the loom and unidirectional fabric (Figure 2b). The hand-lay-up process was used to manufacture the composite.

A DERSA-LASER $3530 \mathrm{~W}$ laser cutting machine was used to cut the test specimens for the mechanical tests. The specimens were cut along the direction of reinforcing fibers at $0^{\circ}, 30^{\circ}, 45^{\circ}, 60^{\circ}$ and $90^{\circ}$ for the first lamina $(22 \%$ fiber volume) and $0^{\circ}, 10^{\circ}, 20^{\circ}, 75^{\circ}$ and $90^{\circ}$ for the second (30\% fiber volume). Test specimens were also obtained for iosipescu shear tests and cut at $90^{\circ}$ (fiber at an angle of $90^{\circ}$ in relation to specimen width). A total of 70 tests were conducted, with at least 5 test specimens for each case.

\subsection{Tensile and Iosipescu tests}

The tensile test measures the ultimate tensile strength, modulus of elasticity and rupture strain of composites. The

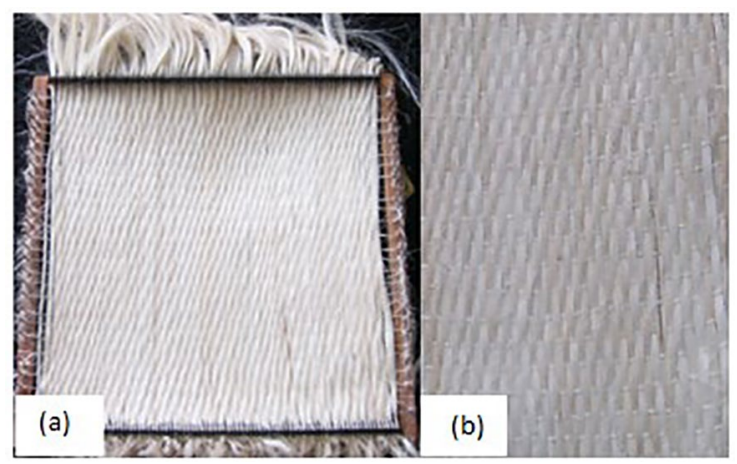

Figure 2. (a) Manual loom, (b) Unidirecional caraua fiber fabric. 
standard test specimens used for tensile tests in continuous fiber composites were manufactured according to ASTM D3039 $9^{17}$. Figures $3 \mathrm{a}$ and $3 \mathrm{~b}$ show the dimensions of the test specimens at $0^{\circ}$ and $90^{\circ}$ used in uniaxial tensile tests.
The iosipescu test consists of a V-notch test specimen that forms a $90^{\circ}$ angle (Figure $3 \mathrm{c}$ ), submitted to force $P$ using an appropriate grip system, and ASTM D5379 ${ }^{18}$ as reference.
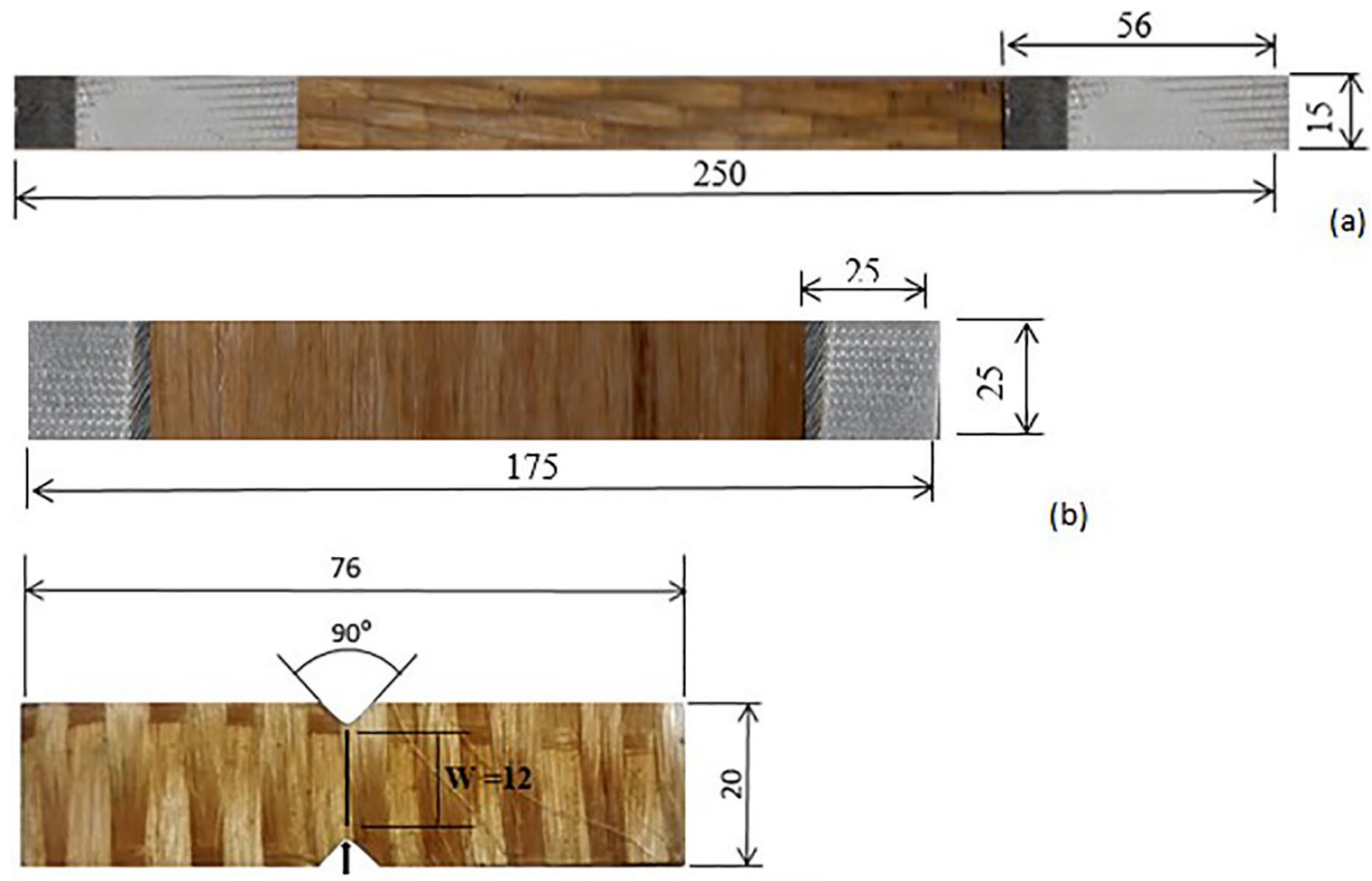

(b)

(c)

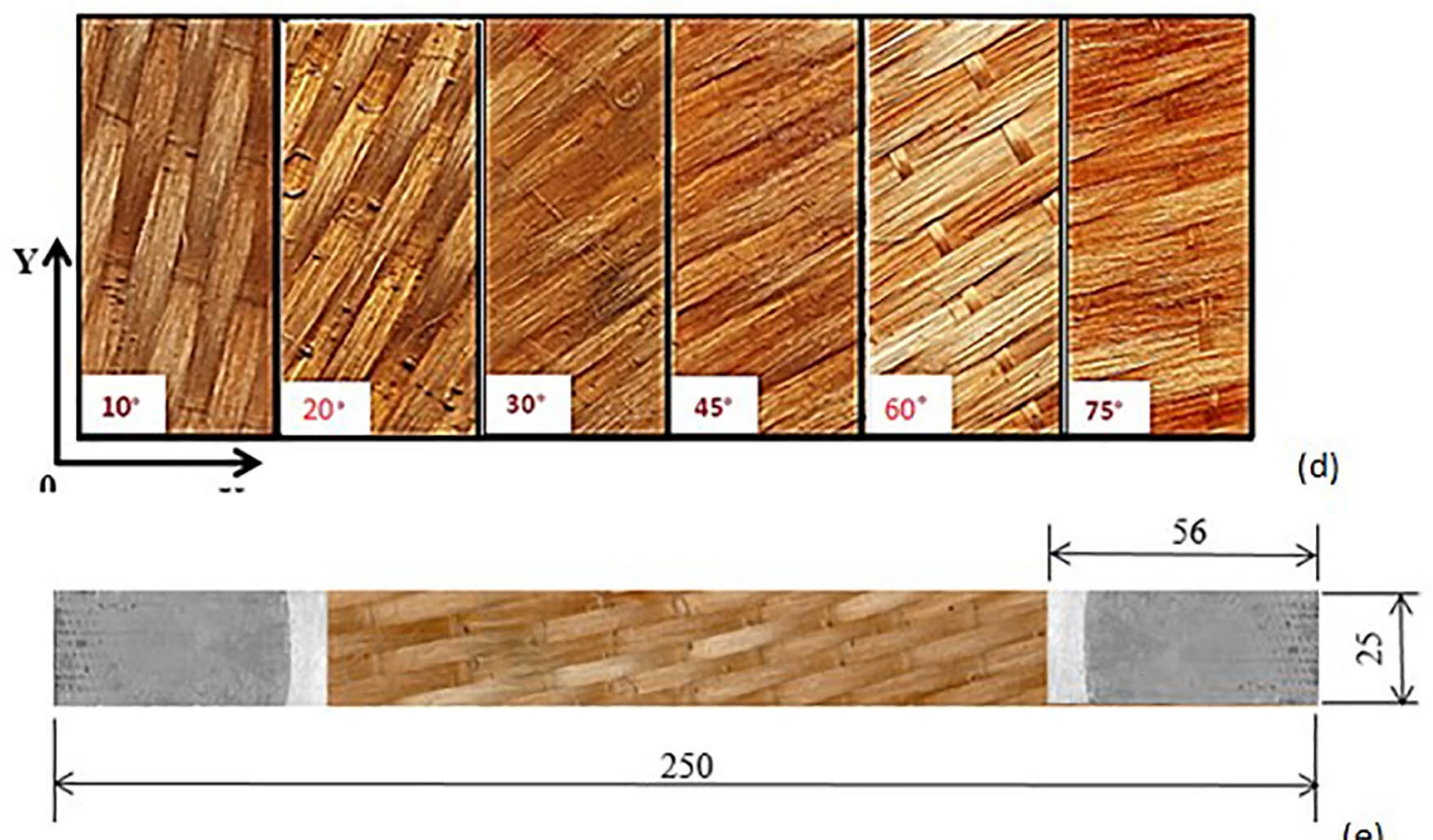

(e)

Figure 3. Test specimen at $0^{\circ}$ (a); Test specimen at $90^{\circ}(\mathrm{b})$; Test specimen dimensions (mm) for the iosipescu test at $90^{\circ}(\mathrm{c})$; Test specimens with the fiber angle used in the two laminas (d); Off-axis test specimen.(e). 
The off-axis tensile test involves applying uniaxial tension to a unidirectional sample so that the fibers (reinforcement) are at an angle tothe main axis.

For this test, specimens were manufactured using ASTM D3039 $9^{17}$, applying fiber angles of $30^{\circ}, 45^{\circ}$ and $60^{\circ}$ and $10^{\circ}$, $20^{\circ}$, and $75^{\circ}$ for the lamina with a fiber volume fraction of $22 \%(C-22)$ and $30 \%$ fiber $(C-30)$, respectively. These directions were obtained using sections of each lamina and their respective reinforcement angles. Figures $3 \mathrm{~d}$ and $3 \mathrm{e}$ exhibit test specimens with the fiber angle used in the two plates. Analysis of variance ( $A N O V A)$ was conducted between the experimental variables exhibited here and the most common failure criteria applied to laminas, as demonstrated in section 2 .

\section{Results and Discussion}

\subsection{Mechanical properties of laminas $C-30$ and C-22}

Analysis of the stress-strain curves of the two laminas (Figure 4) shows almost linear behavior for all the fiber angles. This characteristic is common for on-axis loaded laminas (with load at $0^{\circ}$ or $90^{\circ}$ in relation to the fibers), but may not occur in off-axis loading ${ }^{19}$.

Another important point was the presence of discontinuity curves due to sharp drops in loading during the test, caused by transverse cracks in the matrix of the composite.

Discontinuous stress-strain curves were also reported by Cerchiaro $^{20}$, who studied a unidirectional natural fiber fabric, demonstrating that this behavior is related to localized fractures of one or more fibers and strain redistribution in fibers without breaking.

Figure 4 shows that with an increase in angle, the strength and stiffness of the laminas decline, initially more sharply. Furthermore, lamina $C-30$ is stronger than $C-22$.

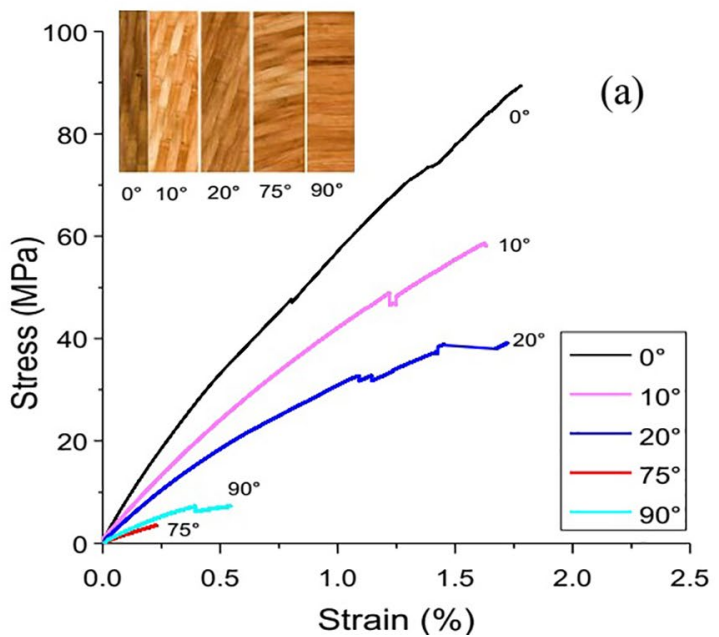

Tables 1 and 2 better illustrate the mechanical properties of these two laminas, since they contain the strength values and engineering constants in the longitudinal and transverse directions of the fiber (Table 1), represented by $E_{1}, E_{2}, v_{12}$, $v_{21}, G_{12}, X, Y$ and $S$ for off-axis loadings (Table 2), depicted by ultimate tensile strength $\left(\sigma_{u l t}\right)$, modulus of elasticity $(E)$ and Poisson's coefficient $(v)$.

As expected, due to its higher fiber content, $C$-30 exhibits greater tensile strength and stiffness than $C-22$, but similar values at larger angles (above $60^{\circ}$ ). This is because the matrix acts as an element of tensile strength in the material.

Another aspect that stands out in Table 1 is Poisson's coefficient $v_{21}$, obtained experimentally. Comparison of this result with that obtained by equation 7 (from the generalized Hooke's law for orthotropic materials) shows that the result of the latter $\left(v_{21}=0.12\right)$ for lamina $C 30$ is close to that observed experimentally $\left(v_{21}=0.11\right)$, but for lamina $C-22$, the difference between these values was significantly higher $\left(v_{21}=0.22\right.$ and $\left.v_{21}=0.16\right)$, with a difference of $27 \%$.

$$
v_{21}=\frac{E_{2}}{E_{1}} v_{12}
$$

The shear test values $\left(S\right.$ and $G_{12}$ ) contained in Table 1 demonstrate once again that the lamina with a $30 \%$ fiber volume fraction displays greater tensile strength (16.21 versus 10.97 $\mathrm{MPa}$ ), but this did not occur with the shear modulus of $C-22(1.5 \mathrm{GPa})$, which was twice as high as that that of $C-30(0.75 \mathrm{GPa})$.

\subsection{Analysis of failure criteria for the curaua fiber-reinforced lamina}

In order to determine whether failure criteria satisfactorily represent the experimental data, the graphs of Figure 5 were constructed for $C-30$ and $C-22$. These graphs reveal that the four failure criteria under study provided a better mechanical behavior model of lamina $C-30$ (Figure 5a) than $C-22$ (Figure 5b), since not all the failure criteria are considered

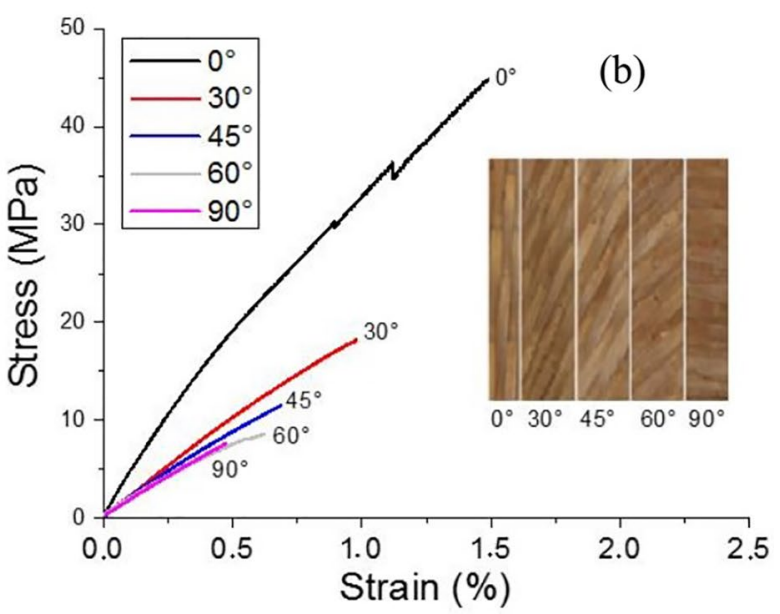

Figure 4. Typical stress-strain curve varying the reinforcement angle of lamina $C$-30 (a) and C-22 (b) test specimens. 
Table 1. Experimentally measured mechanical properties of laminas reinforced with unidirectional curaua fiber fabric.

\begin{tabular}{lccccccccc}
\hline Lamina & $\boldsymbol{X}(\mathrm{MPa})$ & $\boldsymbol{Y}(\mathrm{MPa})$ & $\boldsymbol{S}(\mathrm{MPa})$ & $\boldsymbol{E}_{l}(\mathrm{GPa})$ & $\boldsymbol{E}_{2}(\mathrm{GPa})$ & $\boldsymbol{G}_{l 2}(\mathrm{GPa})$ & $\boldsymbol{v}_{12}$ & $\boldsymbol{v}_{21}$ \\
\hline $\mathrm{C}-30$ & 101.56 & 7.83 & 16.21 & 5.31 & 1.71 & 0.75 & 0.34 & 0.12 \\
$\mathrm{C}-22$ & 50.81 & 10.32 & 10.97 & 4.31 & 2.73 & 1.50 & 0.35 & 0.16 \\
\hline
\end{tabular}

Table 2. Off-axis properties of curaua lamina.

\begin{tabular}{ccccccccccc}
\hline Lamina & Angle & $\boldsymbol{\sigma}_{u l t}(\mathrm{MPa})$ & $\boldsymbol{E}(\mathrm{GPa})$ & $\boldsymbol{v}$ & Lamina & Angle & $\boldsymbol{\sigma}_{u l t}(\mathrm{MPa})$ & $\boldsymbol{E}(\mathrm{GPa})$ & $\boldsymbol{v}$ \\
\hline \multirow{3}{*}{$\mathrm{C}-30$} & $10^{\circ}$ & 54.17 & 3.55 & 0.37 & & $30^{\circ}$ & 19.00 & 3.35 & 0.33 \\
& $20^{\circ}$ & 37.48 & 2.91 & 0.44 & $\mathrm{C}-22$ & $45^{\circ}$ & 13.25 & 2.66 & 0.38 \\
& $75^{\circ}$ & 3.9 & 1.68 & 0.43 & & $60^{\circ}$ & 8.88 & 2.62 & 0.43 \\
\hline
\end{tabular}
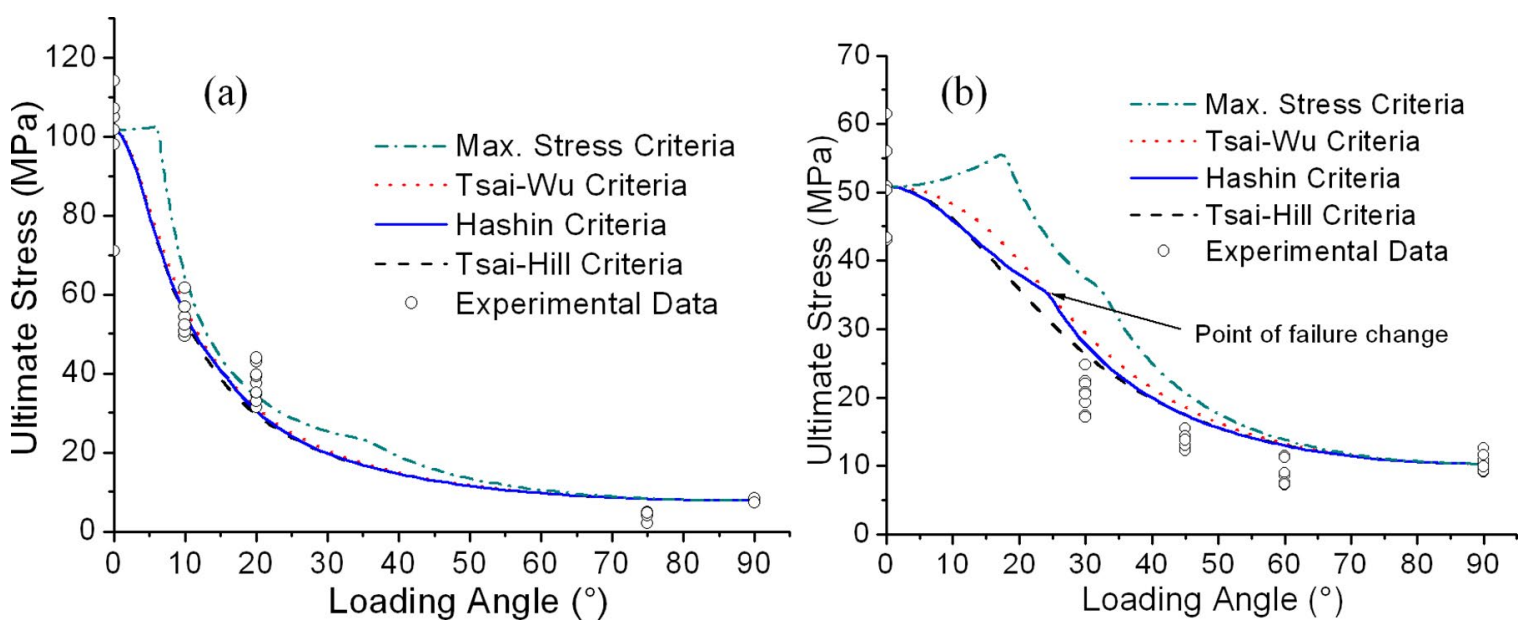

Figure 5. Ultimate stress versus loading angle for lamina $C-30$ (a) and C-22 (b), comparing different failure criteria.

conservative for $C-22$ (Figure $5 \mathrm{~b}$ ). This also occurred for the $75^{\circ}$ angle of $C$-30, where all the failure criteria displayed higher values than those obtained experimentally, with an increase of $50.2 \%$.

Figure $5 \mathrm{~b}$ shows that the Tsai-Hill and Hashin criteria are the closest to the experimental values.

To better evaluate each of the failure criteria, analysis of variance $(A N O V A)$ was conducted between the values obtained for each model and experimental data, considering a $95 \%$ confidence interval. The main data are depicted in Tables 3 and 4, for $C$-30 and $C$-22, respectively.

These tables show the coefficient of determination $\left(R^{2}\right)$ of each failure criterion, maximum coefficient of determination $\left(R_{\max }^{2}\right)$, (in which case the equation would obtain the mean value for each loading angle), and the ratio between the quadratic means $(Q M)$, which is the ratio between the quadratic mean of the failure criterion $\left(Q M_{R}\right)$ and the quadratic mean of the residue $\left(Q M_{r}\right)$, as defined in Equations 8 and 9.

$$
\begin{aligned}
Q M_{R} & =\frac{\sum\left(\widehat{y_{i}}-\bar{y}\right)^{2}}{P-1} \\
Q M_{r} & =\frac{\sum\left(y_{i}-\widehat{y_{l}}\right)^{2}}{n-P}
\end{aligned}
$$

Where $y_{i}$ is the experimental value, $\hat{y}_{i}$ the result obtained by the failure criterion, $\bar{y}$ the mean obtained for experimental data, $P$ the number of parameters in the equation and $n$ the amount of experimental data.

The QM should be compared with the F-distribution with the same number of degrees of freedom, since the more similar these values, the less significant the model in representing the experimental data. Thus, the tables are representative of the model, that is, the ratio between the QM and F-distribution, and the higher this value the more representative the model (failure criterion) in relation to the experimental data.

These analysis of variance (ANOVA) tables show that the failure criterion models are a better representation of lamina C-30 than C-22. Table 3 demonstrates that the coefficient of determination $\left(\mathrm{R}^{2}\right)$ of all the models is close to the maximum value $\left(\mathrm{R}^{2}{ }_{\max }\right)$ and that the ratio between the quadratic means (QM) is 30 times higher than the values obtained by F-distribution, showing that they are representative. Furthermore, the Tsai-Wu and Hashin models exhibited the best failure criteria, with similar values, and the maximum stress criterion results differed most from experimental values.

The findings were less representative for lamina C-22 (Table 4), where the coefficient of determination $\left(\mathrm{R}^{2}\right)$ 
Table 3. Lamina $C$-30 failure criteria (ANOVA).

\begin{tabular}{|c|c|c|c|c|c|}
\hline Criteria & $\mathrm{R}^{2}(\%)$ & $\mathrm{R}_{\max }^{2}(\%)$ & $\mathrm{RQ}=\mathrm{QM}_{\mathrm{R}} / \mathrm{QM}_{\mathrm{r}}$ & $\mathrm{F}_{3,22}$ & $\begin{array}{c}\text { Representativeness } \\
(\mathrm{RQ} / \mathrm{F})\end{array}$ \\
\hline Tsai-Wu & 93.72 & \multirow{4}{*}{95.09} & 111.62 & \multirow{4}{*}{3.05} & 36.61 \\
\hline Hashin & 93.20 & & 108.83 & & 35.69 \\
\hline Tsai-Hill & 93.54 & & 104.06 & & 34.12 \\
\hline Maximum Stress & 92.92 & & 99.35 & & 32.58 \\
\hline
\end{tabular}

Table 4. Lamina $C$-22 failure criteria (ANOVA)

\begin{tabular}{|c|c|c|c|c|c|}
\hline Criteria & $\mathrm{R}^{2}(\%)$ & $\mathrm{R}^{2}{ }_{\text {max }}(\%)$ & $\mathrm{RQ}=\mathrm{QM}_{\mathrm{R}} / \mathrm{QM}_{\mathrm{r}}$ & $\mathrm{F}_{3,38}$ & $\begin{array}{c}\text { Representativeness } \\
(\mathrm{RQ} / \mathrm{F})\end{array}$ \\
\hline Tsai-Hill & 81.84 & \multirow{4}{*}{93.48} & 55.22 & \multirow{4}{*}{2.85} & 19.36 \\
\hline Hashin & 75.91 & & 44.85 & & 15.72 \\
\hline Tsai-Wu & 70.41 & & 37.77 & & 13.24 \\
\hline Maximum Stress & 24.63 & & 22.03 & & 7.73 \\
\hline
\end{tabular}

was significantly different from the maximum coefficient of determination $\left(\mathrm{R}^{2}{ }_{\text {max }}\right)$ for all the failure criteria, and representativeness was lower than that obtained in C-30. Nevertheless, the Tsai-Hill and Hashin criteria are sufficiently representative (more than 15 times) to be applied, and the maximum stress criterion should not be used in this case, since it has a representativeness value of less than 10 and coefficient of determination of $24.63 \%$.

The natural fiber studied here can have different synthetic fiber characteristics, which may have influenced the behavior of lamina C-22 (primarily in the shear test). When the value obtained in the test coincides with half that of the test at $45^{\circ}$, failure criteria tend to better represent the experimental data and are widely used in the literature when no shear tests are performed ${ }^{21}$.

Finally, the Hashin criterion best represents this type of lamina (regardless of fiber volume fraction), since it obtained consistently good results irrespective of the material. Furthermore, it is the only criterion that demonstrates the point of failure change between the fiber and matrix, as shown in Figure 5b.

\section{Conclusions}

The following conclusions can be drawn from the results obtained:

- The tensile tests for C-30 and C-22 obtained tensile strength and modulus of elasticity values that are strongly dependent on fiber direction. This dependence is more marked for low angles, that is, for test specimens in which fibers are closer to the reinforcement direction $\left(0^{\circ}, 10^{\circ}, 20^{\circ}\right.$ and $\left.30^{\circ}\right)$;

- The decline in mechanical strength, due to the fiber inclination angle, is independent of the fiber volume fraction in the lamina;

- $\quad$ The results obtained for the test specimens with a high fiber inclination angle's $60^{\circ}, 75^{\circ}$ and $90^{\circ}$ ) show that mechanical strength is less influenced by the reinforcement direction than the strength of the material, which has a greater effect on the matrix. The higher the fiber inclination angle, the lower the ultimate tensile strength and modulus of elasticity;

- The experimental data of lamina C-30 showed that the four failure criteria studied exhibited satisfactory strength. However, the maximum stress criterion did not display satisfactory behavior for lamina C-22.

\section{References}

1. Amorim FC, Souza JFB, Reis JML. The Quasi-static and Dynamic Mechanical Behavior of Epoxy Matrix Composites Reinforced with Curaua Fibers. Material Research. 2018;21(3):e20170828.

2. Nacas AM, Silva RL, De Paoli MA, Spinacé MAS. Polypropylene composite reinforced with fibrillated curaua fiber and using maleic anhydride as coupling agent. Journal of Applied Polymer Science. 2017;134(25):44913.

3. Mejri M, Toubal L, Cuillière JC, François V. Fatigue life and residual strength of a short- natural-fiber-reinforced plastic vs Nylon. Composites Part B: Engineering. 2017;110:429-441.

4. Rodrigues J, Souza JA, Fujiyama R. Compósitos poliméricos reforçados com fibras naturais da Amazônia fabricados por infusão. Revista Matéria. 2015;20(4):946-960.

5. Almeida NMBG. Estudo estrutural de compósitos de matriz polimérica reforçados com fibras de juta. [Dissertation]. Porto: Faculdade de Engenharia da Universidade do Porto; 2012.

6. Paiva AF. Estudo de compósito de fibra de juta e resina vegetal como substituto dos laminados de fibra de vidro na fabricação da carroceria de veículo de rali. [Dissertation]. Ouro Preto: Federal University of Ouro Preto; 2011.

7. Mohanty AK, Misra M, Drzal LT, eds. Natural Fibers, Biopolymers and Biocomposites: An Introduction. Boca Raton: CRC Press; 2005.

8. Pereira PHF, Rosa MF, Cioffi MOH, Benini KCCC, Milanese AC, Voorwald HCJ, et al. Vegetal fibers in polymeric composites: a review. Polímeros. 2015;25(1):9-22. 
9. Pickering KL, Aruan Efendy MG, Le TM. A review of recent developments in natural fibre composites and their mechanical performance. Composites Part A: Applied Science and Manufacturing. 2016;83:98-112.

10. Kumre A, Rana RS, Purohit R. A Review on mechanical property of sisal glass fiber reinforced polymer composites. Materials Today: Proceedings. 2017;4(2 Pt A):3466-3476.

11. Jenkins CF. Report on Materials of Construction Used in Aircraft and Aircraft Engines. London: Great Britain Aeronautical Research Committee; 1920.

12. Hill R. A theory of the yielding and plastic flow of anisotropic metals. Proceedings of the Royal Society of London. 1984;193(1033):281297.

13. Azzi VD, Tsai SW. Anisotropic strength of composites. Experimental Mechanics. 1965;15(9):283-288.

14. Tsai SW. Strength Theories of Filamentary Structures. In: Schwartz RT, Schwartz HS, eds. Fundamental Aspects of Fiber Reinforced Plastic Composites. New York: Wiley Interscience; 1968. p. 3-11.

15. Tsai SW, Wu EM. A General Theory of Strength for Anisotropic Materials. Journal of Composite Materials. 1971;5(1):58-80.
16. Hashin Z. Failure Criteria for Unidirectional Fiber Composites. Journal of Applied Mechanics. 1980;47(2):329-334.

17. ASTM International. ASTM D3039 / D3039M-14 - Standard Test Method for Tensile Properties of Polymer Matrix Composite Materials. West Conshohocken: ASTM International; 2014.

18. ASTM International. ASTM D5379 / D5379M-12 - Standard Test Method for Shear Properties of Composite Materials by the V-Notched Beam Method. West Conshohocken: ASTM International; 2012.

19. Oliveira FH, Helfer AL, Amico SC. Mechanical Behavior of Unidirectional Curaua Fiber and Glass Fiber Composites. Macromolecular Symposia. 2012;319(1):83-92.

20. Cerchiaro JR. Comportamento mecânico de compósitos com poliéster e tecidos de sisal por moldagem manual. [Dissertation]. Salvador: Federal University of Bahia; 2010.

21. Kumosa M, Odegard G, Armentrout D, Kumosa L, Searles K, Sutter J. Comparison of the $\pm 45^{\circ}$ Tensile and Iosipescu Shear Tests for Woven Fabric Composite Materials. Journal of Composites, Technology and Research. 2002;24(1):3-16. 